\title{
College Students' Experience in Online Asynchronous Peer Feedback in Writing
}

\section{Bethany Marie Cabantac-Lumabi ${ }^{1}$, Rhene C. Tabajen²}

${ }^{1}$ Far Eastern University, Manila, Philippines

${ }^{2}$ University of Makati, Makati, Philippines

Corresponding author: Bethany Marie Cabantac-Lumabi [blumabi@feu.edu.ph]

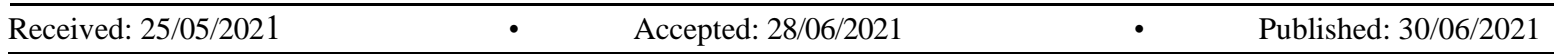

\begin{abstract}
Writing is heavy, tedious, and difficult for college students. Likewise, writing instruction is equally arduous for teachers. The implementation of online and remote classes due to the COVID-19 pandemic becomes an opportunity for students to develop writing through their peers' feedback. This study analyzes the college students' experience and evaluation in online asynchronous peer feedback in writing. One hundred college students in free sections from a private university responded to an adopted, modified, and validated survey questionnaire and focus group discussions to evaluate and validate their experience in online asynchronous peer feedback in writing. The survey results underwent statistical analysis using Statistical Package for the Social Sciences (SPSS), version 20, to determine the weighted mean scores. Thus, the results revealed that the college students have a strong positive experience in online asynchronous peer-feedback in writing with the course facilitator of English language-based subjects. Though online asynchronous peer feedback in writing is an established learning approach, it is not yet maximized in all or most classes of college students. Nevertheless, the study concludes that the positive assumptions, experimentations, and explorations done in online peer feedback in writing remain valuable for college students, especially in their asynchronous writing development.
\end{abstract}

Keywords: online peer feedback; asynchronous learning; remote learning; process-oriented writing; COVID - 19

\section{Introduction}

Writing is a heavy and tedious task for students. Prior to the COVID-19 pandemic, writing has been as difficult as reading and Math. This is evident in the data from the Southeast Asia Primary Learning Metrics (SEA-PLM) 2019, which showed that $45 \%$ of Grade 5 learners in the Philippines have limited ability to present ideas in writing (Balinbin, 2020).

Apparently, the limited writing proficiency of elementary students is carried over to college. At the tertiary level, students can easily find a way to communicate their thoughts verbally, but they behave differently when asked to write them. Undeniably, the college education is heavy on essay writing, book reports, term paper, etc. And despite the long years of writing English as a second language from elementary to senior high school, college students commit constant writing errors such as prevalent grammatical errors, less familiarity with mechanics, and limited English vocabulary. Other serious issues are the lack of comprehensiveness and depth of ideas evident in need of relevant and stronger support. Moreover, a mismatch exists in what college students manifested in the actual writing versus what they recognized and admitted as their errors (Gagalang, 2020). 
Moreover, writing subjects for college are usually incorporated in general education (GE) subjects which freshmen and sophomore students generally take. In fact, the language-based subjects for college students include writing lessons in the last part of the syllabus. Thus, the course facilitators would cover them instantly in class or sometimes never depend on the school calendar. Pablo and Lasaten (2018) concur that writing is frequently accepted as being the last language skill to be acquired. Mastering written skills is a major challenge for learners particularly, writing in English as a second language (ESL). They added that the social and cultural background of the ESL learners that writing is a taboo preventing them from valuing writing subjects. Lastly, they habitually experience lexical, syntactical, and morphological difficulties as influenced by their native language.

Likewise, writing instruction is equally arduous for teachers. For Sihombing (2016), both teaching and assessing writing are difficult. The assessment of writing considers a number of factors: (a) Students' writing ability and what is to test; (b) handwriting ability; (c) writing mechanics; and (d) paragraph construction and development of the main idea, which all vary or differ from one student to another. Moreover, writing instruction and assessment continue along with the teachers struggle to manage the shift from face-to-face instruction to remote education and distance learning, where instructions are disseminated using technological tools such as video conferencing, computer-mediated communication (CMC) and learning management system (LMS).

Despite all of these innovations, responding to student writing remains to be a challenge to teachers, particularly the course facilitators in higher education (Allen \& Katayama, 2015; Alakrash \& Armnazi, 2021). The increasing class size of 35-45 students in a university class makes individual writing instruction impractical for course facilitators because the same number is multiplied to the bulk of papers to check and write meaningful feedback depending on the number of classes they have. As much as they can, course facilitators do not want to compromise their feedback on students' essays because they know students value and use their feedback to write better. Customarily, teachers are the only ones who write corrections and feedback on the students' writing, though sometimes students are asked to check their objective-type quizzes or test.

Collaborative work in the context of writing is a good method that teachers have been utilising, and most students use peer input. Peer feedback, also known as peer review, is based on the concept of cooperation, which holds that learning comes from the shared understandings of numerous learners, and that learning occurs most successfully within interactive peer groups ( $\mathrm{Lu} \& \mathrm{Bol}, 2007)$. It is an important activity that allows writing teachers to help their students receive more feedback on their papers while also providing students with practise in a variety of skills important in the development of language and writing ability, such as meaningful interaction with peers, increased exposure to ideas, and new perspectives on the writing process (Lundstrom \& Baker, 2009).

Timely, the transition to digital learning during the COVID-19 pandemic is a good opportunity to promote online peer feedback as a tool for writing development for college students, which is also beneficial for their facilitators. However, Saeed and Ghazali (2017) recognized the need to explore further online peer feedback, particularly the students' interaction in the writing-revising process through asynchronous, synchronous, or both means of peer review. They believe that limited studies are focused on asynchronous online peer feedback, which is a potential tool for writing development. They agreed with Pena-Shaff and Nicholls (2004) that the delayed time in asynchronous interaction facilitates learners' reflection on their learning.

Thus, this study explored online peer feedback as a prominent feature of process-oriented writing instruction helpful to college students' writing development. Specifically, this paper gives evidence to 
answer the following questions:

1. What is the experience of college students in asynchronous online peer feedback in writing?

2. How do college students evaluate their use of asynchronous online peer feedback in writing?

\section{Literature Review}

\subsection{Concepts in Online Asynchronous Peer Feedback in Writing}

Hayes and Flower (1986) stated that the writing process stresses the technique through which ESL/EFL learners compose their writings rather than the finished texts. Writing, in their opinion, is a dynamic and recurring process that entails reviewing to improve the quality of the text by detecting and correcting weaknesses in the text in terms of language conventions and accuracy of meaning, as well as evaluating the extent to which the text achieves the writer's goals (Hayes \& Flower, 1986). This is the peer feedback perspective, in which learners develop their texts through feedback and text revisions. According to this theory, peer feedback encourages peer revision because it allows students to articulate their thoughts, take more active roles, and negotiate efficient ways of editing their papers (Hu, 2005). It entails the corresponding cognitive processes and language expertise required to handle the issues raised by the students in their draughts (Saeed \& Ghazali, 2017). It has been a significant and beneficial teaching technique in writing classrooms since it motivates students to collaborate on drafting and gives them opportunities to practise English in a meaningful setting (Guardado \& Shi, 2007).

This study is guided by Vigotsky's socio-cultural theory on language learning through mediation in terms of learner interaction. In socio-cultural theory, the social environment is the very core of learning; consequently, Vygotsky advocated that other people interact with the learner; utilise mediatory tools to support the learning process so cognitive development can occur (Hall, 2007). Mediation is essential in the construction and generation of higher mental processes such as logical memory, selective attention, reasoning, analysis, and the metacognitive dimension of problem resolution. According to Vygotsky, these higher mental functions are formed by goal-directed, mediated action. For Vygotsky, the source of mediation was either a material tool (such as utilising a computer); a symbolic system, most notably language, or the behaviour of another human being in social contact. Natural, spontaneous impulses are transformed into higher mental processes, including strategic problemsolving orientations, through mediators in the shape of objects, symbols, and people (Donato \& Mc Cormick, 1994). Indeed, online peer critique in writing can be viewed as a sort of mediation because students collaborate on reconstructing and amending their works.

Furthermore, the concept of online asynchronous peer feedback in writing in this study is based on Garrison, Anderson, and Archer's (2000) "Community of Inquiry" paradigm for online learning settings. This strategy (shown in Figure 1) asynchronously provides a collaborative community of learners at a low cost. It works with the three critical components of a community of inquiry: cognitive presence, social presence, and teaching presence. As important as cognitive presence is in an educational transaction, individuals must feel at ease with one another. Cognitive presence alone will not sustain a vital community of learners (Al-Saggaf \& Rosli, 2021). Such an educational community is fostered by high levels of social presence, as well as high levels of dedication and involvement, both of which are required for the development of higher-order thinking abilities and collaborative work. As a result, social presence is improved in a collaborative learning community. When social presence is joined with proper educational presence, a high level of cognitive presence can be achieved, leading 
to fruitful critical inquiry (Garrison, Anderson, \& Archer, 2000). Evidently, all of these characteristics are present in the process of online peer evaluation for college students' writing improvement.

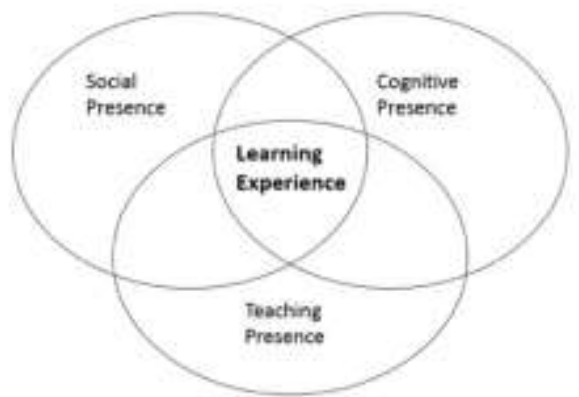

Figure 1. Community of Inquiry (Garrison, Anderson, Garrison and Archer, 2000)

Similarly, as students and teachers celebrate the millennium, the use of computer-mediated communication (CMC) has entered the classroom. In reality, Coit (2004) conducted a peer review with 180 English as a foreign language (EFL) students in an online writing course. She discovered, through qualitative data analysis, that the bulk of modifications made by peer reviewers were surface corrections, which may have occurred during face-to-face discussions when additional options for meaning alterations or corrections arose. Despite the fact that there were fewer meaning-level adjustments in this study, the significant number of corrections suggests that the students took their work seriously and offered meaning-level corrections nearly $20 \%$ of the time. Furthermore, students offered final good remarks at the end of nine out of ten texts, which covered the overall organisation and content of the book, as well as ideas for specific areas to be worked on. Finally, the low number of false repairs was highly encouraging because the corrector frequently showed uncertainty about his/her fixes, making the writer less inclined to simply accept them as such. As a result, she finds that, despite the limits of the data, the peer review process enabled the students to develop a sense of a specific audience and to receive regular feedback on what they wrote. There would have been little motivation to finish the weekly assignments if they had not been able to receive regular feedback on their progress. Without the student revisions, there would have been no motivation for the students to write a second draft of each text, which is an important step in light of research indicating that the multi-draft process leads to stronger essays.

Technology may, in fact, be efficiently combined with writing and language development. For more than 25 years, computer-assisted language learning (CALL) has been utilised and proven in several studies (Bush, 2013). Writing instructions are incorporated in information technology, and the emergence of the Internet has increased the popularity of online language learning/writing. Lin and Yang (2011) evaluated the students' experiences with and perceived efficacy of incorporating Wiki technology and peer evaluation into an English writing course in their project in a writing class of college students. As teachers and researchers, the authors used a socio-cultural theoretical approach to investigate the processes of conducting Wiki-based English writing courses with peer feedback at the college level. Students said that they noticed more development in grammatical mechanics and style than in the organisation and content. Although meeting some challenges in using this new tool, most learners felt confident in their abilities to apply Wiki and peer feedback to writing training. Their research showed that students' positive attitudes toward peer feedback were the outcome of meaningful social connection in the worthwhile writing activity, as well as the benefits of delivering and receiving peer evaluation.

The impact of online peer feedback on student writing progress is seen in both synchronous and asynchronous learning. Al-Olimat and AbuSeileek (2015), for example, conducted one controlled 
group and three experimental groups of Grade $10 \mathrm{EFL}$ students using computer-mediated corrective feedback modes such as teachers' feedback (students who received feedback only from the teacher), students' feedback (students who provided and received feedback from their peers), and both (students who received and provided feedback from both teachers and peers). Their findings revealed that computer-mediated corrective feedback provides an excellent opportunity for teaching writing skills. In comparison to the group that received no feedback, students performed better on the writing performance exam in the CMC environment. Furthermore, data confirms that students who received remedial criticism outperformed pupils who did not receive corrective feedback. Thus, providing corrective feedback may improve students' writing performance because the study's findings demonstrated that instructor and student feedback was the most successful technique in increasing students' writing competence. On the writing post-test, students in the teacher and student feedback group outperformed participants in the other conditions in most writing qualities related to punctuation, grammar, and vocabulary. This could be that punctuation is easier to learn than spelling, organisation, substance, grammar, and vocabulary.

\subsection{Peer Feedback in College Writing}

In two studies in higher education, Pol et al. (2008) investigated the relationships between the nature of feedback, its reception by the receiver, and its subsequent use in the revision of students' texts using different tools to facilitate the process of providing peer feedback. In their first study, they discovered significant favourable relationships between concrete revision suggestions and features of content and style. Furthermore, the more feedback was valued as essential, the more students used it to modify their texts. However, the findings of their second study found significant connections between feedback with the function of analysis, assessment, and recommending improvements and feedback on both the content and style of a text on the one hand, and whether or not a text had been altered on the other. Furthermore, the more students who agreed with the offered feedback, the more beneficial the feedback was rated; and the more students who agreed with the provided feedback, the more they altered the related areas of their texts. Finally, students provided less evaluative input and more feedback with revision ideas in the annotation system than in board work.

Peer feedback, on the other hand, can be utilised as a writing assessment in college. Mutwarasibo (2016) investigated how undergraduate students at the National University of Rwanda experienced peer assessment of group writing as one way to improve the quality of their learning. Positive results demonstrated that some students who were unfamiliar with peer assessment viewed it as a learning opportunity. Despite the fact that most students did not appear to associate it with the academic environment, they valued it for their future vocation. Based on the assessment criteria, the students' essays were assessed to be fair and acceptable. Some students, however, suggested that it would have been more reasonable to give more weight to some elements, such as reasoning and proof. Because peer evaluation tasks change in a variety of ways, the assessment criteria and their weighting can also differ to meet diverse contexts and scenarios. Another context of the study was to see if students would feel empowered to participate in the process of peer assessment as a means of adding variety to the dominant lecturer-controlled assessment. Half of the students believed that their grades would be reduced if the lecturer marked their essay scripts, while the rest believed that they would be the same or slightly upgraded.

The feasibility and usefulness of peer feedback to ESL teachers and students have been explored in the qualitative study of Thokwane (2011). The student participants of her study noted that peer feedback is beneficial to their academic writing skills for it enabled them to identify their writing weaknesses, something they would not have been able to do by themselves; it created a community of 
learners that helps them clarify written concepts and phrases in their essays; it was an effective instrument to clearly communicate their ideas to their readers, and it helped them with their grammar mistakes. As for the teacher participants, peer feedback enlightened their understanding of the required process approach in teaching academic writing in ESL, especially on the role and significance of feedback. Thus, her study concludes that teachers may save time for grading papers upon using peer feedback in students' writing. It develops trust and partnership between teachers and students as coteachers to discuss and help them with the writing corrections in small groups.

\subsection{Challenges in Peer Feedback in Writing}

The writing process is definitely difficult for pupils, particularly those studying English composition. Similarly, for various reasons, the peer criticism method to writing may be as difficult for some kids. Cultural background, in particular, has a considerable impact on peer criticism in the writing of some ESL Japanese students. Guardado and Shi (2007) provided anonymous peer electronic feedback to students to critically examine their peers' writing, while a few wished they knew who had reviewed their articles. As a result, many participants made insecure peer comments; some provided positive feedback or sugarcoated their negative feedback as reviewers; some did not follow their revisions because they thought peer feedback was useless; and many found textual exchanges more difficult than face-to-face interaction. As a result, the study concluded that the lack of interaction turned online peer feedback into a one-way communication process, leaving a significant portion of peer remarks unanswered and, as a result, potentially unrealized.

Another argument discovered in peer criticism in writing among students is the bias. This form of prejudice was termed as friendship marking or over-marking by Prins et al. (2005, in Guardado \& Shi, 2007). Over-marking may appear excessively difficult for students who are adamant that the grades they were assigned were fair (i.e. not too high or too low in students' interpretations). Similarly, Saito and Fujita (2004, in Bijami, 2013) stated that several types of bias emerged from a number of peer feedback studies, including reference, purpose (development vs grading), feedback (effects of negative feedback on future performance), and collusive (lack of difference) bias.

Furthermore, the process of commenting on a classmate's written work is challenging a student's writing skill and credibility. Some peers are likely to comment on surface errors; sentence- level errors (local errors) rather than on the content and ideas (global errors); and give advice that does not help revision. Students prefer teacher feedback to peer feedback because they perceived that a teacher is qualified to provide them with useful comments (Bijami, 2013). This perception is established in teacher-centered classrooms, where the teacher is described as the only source of authority for giving constructive comments. In addition, these surface-level comments may not have addressed the content and correction needed to improve the quality of their peers' final texts (Mutwarasibo, 2016).

Nevertheless, students' challenges in writing are not their own or their peers' responsibility only since their writing teachers have a significant role in their writing process. For this reason, Rollinson (2005) attests that peer response in the writing classroom is a time-consuming activity, but it may not be time wasted. Specifically, college students, as young adults, have rich and various writing and reading experiences. Thus, peer feedback is a good opportunity for them to practice becoming critical readers, as teachers help them toward becoming more self-reliant writers - self-critical and skillful to self-edit and revise their writing. To achieve this, Rollinson (2005) emphasized that teachers should adequately set-up and train their students on the benefits of the peer feedback activity considering their age, cultural background, class size, and interlanguage level, which may significantly influence the overall outcomes. Definitely, for the teacher who perhaps wishes to escape from the tyranny of the red 
pen (if only temporarily) and explore an activity that can complement her own feedback to her students' writing, collaborative peer group response is a potentially rewarding option.

\section{Material and Methods}

\subsection{Research Design}

The descriptive quantitative design was employed in this study to demonstrate the utility and promise of online peer feedback for the writing growth of college students. Quantitative research is concerned with collecting numerical data and generalising it across groups of individuals or explaining a specific phenomenon. A descriptive study, on the other hand, is governed by the following rules: subjects are generally measured only once; the intention is to only establish associations between variables; and the study may include a sample population of a hundred or more subjects to ensure that a valid estimate of a generalised relationship between variables is obtained (USC, 2021).

\subsection{Participants}

The questionnaire was employed online as part of the college students asynchronous learning in their GE subjects (i.e. Speech Communication and College Academic Skills in English - CASE) prior to the suspension of face-to-face classes due to the COVID-19 pandemic. One hundred college students from a private non-sectarian university in Manila, Philippines, where blended learning (online and face-to-face instruction) and student-centered learning (active learning) are included in the curriculum. They belong to free sections which means in higher education, a free section consists students in different courses (i.e. Accountancy, Medical Technology, Architecture, Hotel and Restaurant Management, Communication, Education, and Interdisciplinary Studies) and year levels (i.e. first and second year. The same set of students joined the focus group discussions during face-to-face classes to verify the data they presented on the survey questionnaire. Lastly, 13 language course facilitators (with more than five-year teaching experience) from different higher education institutions in National Capital Region (NCR) were selected for an unstructured interview to triangulate the college students experiences and evaluation on online peer feedback for writing development.

\subsection{Research Instrument}

The study instrument, a survey questionnaire, was specifically adapted from Lei (2017) and modified to fit the current research situation. The Likert-scale survey questionnaire was used to measure the experience and evaluation of college students in online asynchronous peer feedback in writing. A Likert scale posits that an attitude's strength/intensity is linear, i.e. on a continuum from strongly agree to strongly disagree, and that attitudes can be quantified (McLeod, 2019). Cronbach's alpha for the complete pilot survey composite index was 0.88 , indicating that the pilot survey instrument scores were reliable. Cronbach's alpha is a measure of internal consistency, or how closely linked a group of things is. It is regarded as a scale reliability metric. A "high" alpha number does not mean that the measure is one-dimensional. Cronbach's alpha is not a statistical test; instead, it is a measure of internal consistency (Bruin, 2006).

\subsection{Data Analysis}

Moreover, the 15-item Likert-scale survey questionnaire was divided into two latent constructs of seven items for the college students experience in online asynchronous peer-feedback in writing and eight items for their evaluation in online asynchronous peer-feedback in writing. It has 4-point response scales such as 1=Strongly Disagree (SD)/ Never Experienced (NE), 2=Disagree (D)/ Less Experienced 
(LE), 3=Agree (A)/ Experienced (E), and 4=Strongly Agree (SA)/ Highly Experienced (SE), which undergone statistical analysis with the use of Statistical Package for the Social Sciences (SPSS), version 20 , to determine the weighted mean scores.

\section{Results}

Table 1 presents the college students' experience in online asynchronous peer feedback in writing based on the statistical analysis of the survey questionnaire results. In the first indicator, the college students highly experienced online peer feedback in writing with the course facilitator in English language-based subjects. Likewise, they highly experienced that course facilitator: gives clear instructions before doing the online asynchronous peer feedback in writing; instructs the rubrics for the online peer feedback process, and instructs the rubrics for the online peer feedback process. In addition, they are highly experienced online asynchronous peer feedback in writing with regard to comments and corrections on content, grammar, and mechanics (i.e. spelling, punctuation, capitalization, margin, etc.). On the other hand, the college students experienced online asynchronous peer feedback in writing activities in English language-based subjects only. Also, they experienced that it is practiced in all/most classes, and the written output of the online asynchronous peer feedback is facilitated by the course facilitator with the class.

Table 1. College Students' Experience in Online Asynchronous Peer Feedback in Writing

\begin{tabular}{|c|c|c|}
\hline Indicator & Mean & $\begin{array}{c}\text { Descriptive } \\
\text { Interpretation }\end{array}$ \\
\hline $\begin{array}{l}\text { 1. The course facilitator of English language-based subjects always uses } \\
\text { online asynchronous peer feedback in writing in class. }\end{array}$ & 3.26 & $\begin{array}{c}\text { Highly } \\
\text { Experienced }\end{array}$ \\
\hline $\begin{array}{l}\text { 2. The course facilitator gives clear instructions before doing the online } \\
\text { asynchronous peer feedback in writing in class. }\end{array}$ & 3.39 & $\begin{array}{c}\text { Highly } \\
\text { Experienced }\end{array}$ \\
\hline $\begin{array}{l}\text { 3. The course facilitator instructs the rubrics for the process of online } \\
\text { asynchronous peer feedback in writing. }\end{array}$ & 3.32 & $\begin{array}{c}\text { Highly } \\
\text { Experienced }\end{array}$ \\
\hline $\begin{array}{l}\text { 4. Online asynchronous peer feedback in writing is usually used in } \\
\text { writing activities in English language-based subjects only. }\end{array}$ & 3.09 & Experienced \\
\hline $\begin{array}{l}\text { 5. Online peer feedback in writing is usually about comments and } \\
\text { corrections on content, grammar, and mechanics (i.e. spelling, } \\
\text { punctuation, capitalization, margin, etc.) }\end{array}$ & 3.51 & $\begin{array}{c}\text { Highly } \\
\text { Experienced }\end{array}$ \\
\hline $\begin{array}{l}\text { 6. Online asynchronous peer feedback in writing is practiced in all/most } \\
\text { classes. }\end{array}$ & 2.56 & Experienced \\
\hline $\begin{array}{l}\text { 7. The course facilitator facilitates the output of the online asynchronous } \\
\text { peer feedback in writing with the class. }\end{array}$ & 3.20 & Experienced \\
\hline Average Weighted Mean & 3.19 & Experienced \\
\hline
\end{tabular}

Legend: DI-Descriptive Interpretation: 3.26-4.00=Highly Experienced; 2.51-3.25=Experienced; 1.762.50=Less Experienced; 1.00 - 1.75=Never Experienced

Meanwhile, the college students evaluated online asynchronous peer feedback in writing for their writing development, as presented in Table 2. These are the descriptive interpretation results of the indicators from the survey questionnaire. They strongly agree that they take online asynchronous peer feedback in writing positively, both on their writing and their classmate's written output. In fact, they consider online peer feedback as a chance to exchange ideas with their peers through writing; and they suggest that peer feedback should be used more often, not only in skill-based subjects (i.e. general education), but also in content-based instructions (i.e. professional subjects). Furthermore, they strongly agree that online asynchronous peer feedback in writing, compared to their course facilitator's feedback, creates a relaxing atmosphere that lessens the student's stress in writing. For them, it encourages the students to involve more in English writing; it creates a relaxing atmosphere which lessens the student's stress in writing compared to the course facilitator's feedback, and it is a way to know their own weakness in writing and reciprocate it with knowledge and suggestions from others. 
In contrast, the college students agree that they trust their classmate's ability to provide qualified feedback on my written output and that online asynchronous peer feedback in writing is more interesting and efficient than any peer feedback.

Table 2. College Students' Evaluation of Online Asynchronous Peer Feedback in Writing

\begin{tabular}{|c|c|c|}
\hline Indicator & Mean & $\begin{array}{c}\text { Descriptive } \\
\text { Interpretation }\end{array}$ \\
\hline $\begin{array}{l}\text { 1. I take online asynchronous peer feedback in writing positively, both in } \\
\text { my writing and my classmate's written output. }\end{array}$ & 3.36 & Strongly Agree \\
\hline $\begin{array}{l}\text { 2. I trust my classmate's ability to provide qualified feedback on my } \\
\text { written output. }\end{array}$ & 3.13 & Agree \\
\hline $\begin{array}{l}\text { 3. I consider online asynchronous peer feedback in writing as a chance to } \\
\text { exchange ideas with my peers through writing. }\end{array}$ & 3.57 & Strongly Agree \\
\hline $\begin{array}{l}\text { 4. Online asynchronous peer feedback, compared to my course } \\
\text { facilitator's feedback, creates a relaxing atmosphere which lessens the } \\
\text { student's stress in writing. }\end{array}$ & 3.28 & Strongly Agree \\
\hline $\begin{array}{l}\text { 5. Online asynchronous peer feedback in writing encourages the students } \\
\text { to involve more in English writing. }\end{array}$ & 3.44 & Strongly Agree \\
\hline $\begin{array}{l}\text { 6. Online asynchronous peer feedback in writing is a way to know the } \\
\text { student's own weakness in writing and reciprocate it with knowledge } \\
\text { and suggestions from others. }\end{array}$ & 3.52 & Strongly Agree \\
\hline $\begin{array}{l}\text { 7. Online asynchronous peer feedback in writing is more interesting and } \\
\text { efficient than any peer feedback. }\end{array}$ & 2.88 & Agree \\
\hline $\begin{array}{l}\text { 8. I suggest asynchronous peer feedback in writing should be used more } \\
\text { often, not only in skill-based subjects (i.e. general education), but also } \\
\text { in content-based instructions (i.e. professional subjects). }\end{array}$ & 3.63 & Strongly Agree \\
\hline Average Weighted Mean & 3.35 & Strongly Agree \\
\hline
\end{tabular}

Legend: DI-Descriptive Interpretation: 3.26-4.00=Highly Experienced; 2.51-3.25=Experienced; 1.76$2.50=$ Less Experienced; $1.00-1.75=$ Never Experienced

\section{Discussion}

\subsection{Experience in Online Asynchronous Peer Feedback in Writing}

The results of the survey questionnaire were analyzed statistically and descriptively interpreted. And, it was found out that the college students are very familiar with online asynchronous peer feedback in writing because they always use it especially with their course facilitator in English language-based subjects (e.g. Speech Communication and CASE). Moreover, they have highly experienced getting clear instructions from the course facilitator before doing the online peer feedback process with the rubrics for assessing their peer's online work. In addition, they have strong practical knowledge of online asynchronous peer feedback in writing in giving comments and corrections on content, grammar, and mechanics (i.e. spelling, punctuation, capitalization, margin, etc.) of their peers.

In light of the socio-cultural theory, Vygotsky established the "zone of proximal development (ZPD) as the site where social forms of mediation develop. It differentiates the achievements when a person is learning alone (asynchronous) and when learning with support from someone else (peers/ classmates) and/or object (i.e. computer) (Lantolf, 2000). The college students based their response to their ZPD as experienced in their online asynchronous peer feedback in writing. Their strong positive response means that online asynchronous peer feedback in writing sustained the ZPD because they have worked jointly as co-constructors of the texts, and their expertise emerges in the comments and corrections.

On the other hand, the college students experience on online asynchronous peer feedback in writing activities in English language-based subjects only matches their equal experience on online 
asynchronous peer feedback in writing in all/most classes (2.56 - experienced). These results prove that online asynchronous peer feedback in writing is an established learning approach, but it is not yet maximized in all/most classes. This result disproves the claim of Thokwane (2011) that the 21 st century teachers use online peer feedback more frequently than before because some scholars and researchers report that it is very effective in improving students' writing performance. Thus, online asynchronous peer feedback in writing should be encouraged not only to English-based subjects but to content subjects as well.

Meanwhile, the college students' experience in the facilitation of their output in online asynchronous peer feedback by their course facilitator with the class, calls for a wider implementation of task-based activities in student-centered learning approach. Part of the process of the community of inquiry theory (Garrison et al., 2000) is the teaching presence element which is played by the teacher. Facilitation is the second function of the teacher in this model. It may be shared among the teacher and students appropriately in higher education. This element aims to support and enhance social and cognitive presences to realize the course outcomes. Likewise, task-based learning employs peer feedback activities that thrust students' roles, particularly in writing tasks. Peer feedback may positively affect students toward writing and offers a student-centred assessment to teachers of writing (Lumabi, 2020).

Despite the positive results of the survey, the course facilitators explained their reasons for their limited use of online peer feedback. Ten out of 13 language course facilitators admitted that the process of peer feedback is time-consuming because aside from giving several instructions to the class, they could not monitor the students, especially with populated classes. Similarly, Grimes and Warschauer (2010); El Ebyary and Windeat (2010) noted in their articles that feedback on writing was described as a time-consuming task by instructors because they may not give individualized, immediate, contentrelated feedback to multiple drafts. Thus, Guardado and Shi (2007) recommend for follow-up class discussions after students have received the online peer feedback; it could organize students to discuss and clarify the problematic comments together (synchronously). The course facilitators should join these follow-up discussions because with their guidance, who knows good writing, students build up their confidence in following the feedback effectively in their revisions.

\subsection{Evaluation in Online Asynchronous Peer Feedback in Writing}

To achieve the objective of the current study, the college students' evaluation in online asynchronous peer feedback in writing is surveyed and analyzed. Results reveal that college students take online asynchronous peer feedback in writing positively on their own and their classmate's written output. The strong interest of the college students' response is justified theoretically by Garrison et al. (2000) because computer conferencing is considered in creating a competitive community of learners supporting critical thinking. In particular, computer conferencing is now the new era of distance education because it can create a collaborative community of learners asynchronously in a costeffective manner. Likewise, the use of computers in assessing written responses is pedagogically desirable, as it can be integrated with existing assessment methods and strategies; increase the frequency of feedback; and broaden the range of assessed skills (El Ebyary \& Windeat, 2010). The positive reaction of college students in online asynchronous peer feedback in writing has been observed by the course facilitators as they described it in the interview.

For this reason, the college students evaluated and highly concurred that online asynchronous peer feedback in writing to be used more often, not only in language activities, but also in content-based instructions. In other words, college students recommend it to be used frequently, not only in skill or language-based subjects (i.e. general education) but also in content-based instructions (i.e. professional 
subjects). This result was seconded by the course facilitators in the interview since most of them practice online asynchronous peer feedback in writing of their student teachers in their professional education subjects. Oxford (2017) agrees that in content-based instruction, students practice all the language skills in a highly integrated, communicative fashion while learning content such as science, mathematics, and social studies. This perspective is covered in the socio-cultural theory because in language learning, initially unfocused learning actions may become adjusted and modified based on how language learning is mediated. Mediation is, thus, the instrument of cognitive change (Donato \& McCormick, 1994).

Moreover, online asynchronous peer feedback in writing is evaluated by the college students as a chance to exchange ideas with their peers through writing, specifically writing more in English because using electronic communication can avoid the possible embarrassment students may experience in face-to-face interaction ( $\mathrm{Lu} \& \mathrm{Bol}, 2007$ ). Besides, computer-mediated corrective feedback methods and techniques may support students when receiving corrective feedback in a manner that may aid them more in the development of their writing performance (Al-Olimat \& AbuSeileek, 2015). College students put a value on peer feedback because it is a way for them to know their own weakness in writing and reciprocate it with knowledge and suggestions from others. Theoretically, Garison et al. (2000) argue that in the social presence, socio-emotional interaction and support are important and sometimes essential in realizing meaningful and worthwhile educational outcomes. Here, collaboration helps learners draw a shared experience for the purposes of constructing and confirming meaning in their texts. In fact, most of the course facilitators mentioned in the interview that they get impressed to see the development of the submitted essays of their college students who underwent online asynchronous peer feedback in writing. They usually require them to submit their online asynchronous peer-reviewed draft with their revised essay for comparison and reference.

In comparison, college students prefer online asynchronous peer feedback in writing to their course facilitator's feedback because it creates a relaxing atmosphere that lessens their stress in writing. This result indicates that writing becomes less stressful when collaborated with peers, than the course facilitators. Thus, it promotes independent learning and writing, which is one of the goals in asynchronous learning. Based on the study of Saeed et al. (2018), asynchronous peer feedback fosters learners' engagement in revision-oriented feedback. Such peer feedback mediates learners' understanding of global and local issues in writing. It also serves as scaffolding that assists learners, especially those who receive such feedback or scaffolds, to attend to issues in their texts and revise them accordingly.

Furthermore, they realized that online peer feedback in asynchronous learning serves as social interaction. Learners establish a shared understanding, admit their misunderstandings or errors, and create a friendly atmosphere and mutual respect. In turn, this will motivate learners to accept one another's criticism, integrate their peers' suggestions into revising their writing, and pursue their learning outside formal writing courses for further development of ESL/EFL writing (p. 56). Similarly, most of the course facilitators shared in the interview that they give points even to feedback on personal qualities - a form of pure "praise, rewards and punishment" without task-related information such as "Well done", Great job", etc. (Noroozi et al., 2016). In the socio-cultural learning design, the peers' role provides a social environment where learners develop competency in tool use (Hall, 2007) by giving constructive corrections and personal commendations.

On the other hand, the college students' trust to their classmate's ability to provide qualified feedback results to lower mean. Despite their preference of peer's feedback versus the course facilitator, college students are still expecting quality and reliable comments on their written outputs. 
It has been noted that not all students fully trust in the competence of the learning peers to evaluate their work. This is actually one of the challenges of peer feedback: distrust in learning peer's quality of feedback. Thus, Noroozi et al. (2016) recommend the need for arranging learning environments for students to willingly and with a high degree of motivation engage in the online asynchronous peer feedback process for learning and writing. As for the interview result, some of the course facilitators impose the value of integrity whenever they facilitate online asynchronous peer feedback in writing. Integrity covers honesty, uprightness, and good character in giving and receiving peer feedback online which all writers must develop.

\section{Conclusion}

Teachers feedback online is undeniably valuable in their students' performance particularly in their writing development. Likewise, students should also be given an opportunity to comment to improve others' written works purposefully using technology and the Internet. Hence, despite its limitations, the results of this study conclude that the positive assumptions, experimentations, and explorations done in online peer feedback in writing remain valuable for college students, especially in their asynchronous writing development. It is then realized that online asynchronous peer feedback in writing would credibly help college students or future professionals develop transferable skills in giving evaluation, constructive comments, or encouragement discourse.

The results and conclusion of this study call for support for online asynchronous peer feedback in writing of college students through some recommendations. First, online peer feedback shifts students and teachers' roles in asynchronous settings, giving students more learning opportunities and facilitating skills to teachers. Second, since most students are positive about online peer feedback for writing development, it can be regularly employed not only in academic writing tasks but also in other online outputs as long as it is done in asynchronous learning since the students are not time-pressured and can freely think of appropriate comments on their peer's work. Lastly, the conduct of online peer feedback requires careful consideration from course facilitators. Rollinson (2005) noted that an adequate set-up and trained class can fully benefit from peer feedback activity with considerations of age, cultural background, class size, and interlanguage level, which may significantly influence overall outcomes.

\section{Acknowledgement}

The main author is grateful to her loving husband, Robert Bon, and her adorable son, Mateo Bevon. She thanks the Cabantac and Casia families, especially her parents, Antonio (+) and Victoria, and siblings, Vianne and Anthony Victor for their love and support. She expresses her gratitude to all her mentors in the graduate school of Philippine Normal University for inculcating the culture of research to their students. Also, she shows her appreciation to the friendship of her colleagues in the academe, in particular Juland Salayo, for inspiring her to publish her researches. Most importantly, she is indebted to the contribution of her beloved college students, then and now, which made her researches remarkable. And, above all, she gives all the praises and glory to Lord Jesus Christ.

The co-author would like to thank his mother, Mama Linda, and siblings namely, Niña, Virlyn, Jeddoh, Angelo, Mary Grace, and his nieces and nephews, Stacey, Swency, Kia, Jenlex, Lynelle, and $\mathrm{VJ}$ for being the bastion of his strength and for sharing with him happy moments and unconditional love. He is also grateful to have a friend who encourages him to conduct the study, Bethany Marie Lumabi. He would like to thank the students who participated in the conduct of the study in this challenging time. Lastly, he praises and gives glory to Our Lady of Manaoag and the Lord Jesus Christ, for truly existing in his life. 


\section{Author Contribution}

Both authors agree on the amount of their substantial contribution in the fulfillment of this research article. The main author initiated the study including the introduction, review of literature, collection of data, discussion of results, conclusion, and submitted version. While, the co-author conceptualized the research design, use of statistical tool, data analysis, and abstract. Both are personally accountable for the authors' contributions and for ensuring that questions related to the accuracy or integrity of any part of the work, even ones in which the author was not personally involved, are appropriately investigated, resolved, and documented in the literature.

\section{Conflict of Interest}

The authors declare no conflict of interest.

\section{References}

Alakrash, H. \& Armnazi, M. (2021). Factors Affecting the Application of Communicative Language Teaching CLT in Syrian Schools. TESOL and Technology Studies, 2(1), 1-14.

Allen, D. \& Katayama, A. (2015). Relative second language proficiency and the giving and receiving of written peer feedback. Elsevier System, 56, 96-106.

Al-Olimat, S. I. \& AbuSeileek, A. F. (2015). Using computer-mediated corrective feedback modes in developing students' writing performance. Teaching English with Technology, 15(3), 3-30.

Al-Saggaf, M. A., \& Rosli, A. S. (2021). The Level of Community of Inquiry (CoI) Presences in Online Classes among MSU BTESL Students. TESOL and Technology Studies, 2(1), 65-78.

Balinbin, A. (2020, December 3). Filipino students falling behind in reading, writing levels in Southeast Asia. Retrieved from https://www.bworldonline.com/filipino-students-falling-behindin-reading-writing-levels-in-southeast-asia/

Bijami, M., Kashef, S. H., \& Nejad, M. S. (2013). Peer feedback in learning English writing: Advantages and disadvantages. Journal of Studies in Education, 3(4), 91-97.

Bruin, J. (2006). Newtest: command to compute new test. UCLA: Statistical Consulting Group. Retrieved from https://stats.idre.ucla.edu/spss/faq/what-does-cronbachs-alpha-mean/

Bush, M. D. (2013). Computer-assisted language learning: From vision to reality?. CaLICO Journal, 25(3), 443-470.

Coit, C. (2004). Peer review in an online college writing course. ICALT' 04 Proceedings of The IEEE International Conference on Advanced Learning Technologies, 900-903.

Donato, R., \& MacCormick, D. (1994). A sociocultural perspective on language learning strategies: The role of mediation. The modern language journal, 78(4), 453-464.

El Ebyari, K. \& Windeat, S. (2010). The impact of computer-based feedback on students' written work. International Journal of English Studies (IJES), 10(2), 121-142.

Hayes, J. R., \& Flower, L. S. (1986). Writing research and the writer. American psychologist, 41(10), 1106.

Hu, G. (2005). Using peer review with Chinese ESL student writers. Language Teaching Research, 9(3), 321-342

Gagalang, J. L. . (2020). Assessing Deficiencies in Composition Writing: A Case of Filipino College Freshmen Learners. PalArch's Journal of Archaeology of Egypt / Egyptology, 17(1), 307-316.

Garrison, D. R., Anderson, T., \& Archer, W. (2000). Critical inquiry in a text-based environment: Computer conferencing in higher education model. The Internet and Higher Education, 2(2-3), $87-105$.

Grimes, D. \& Warschauer, M. (2010). Utility in a fallible tool: A multi-site case study of automated writing evaluation. Journal of Technology, Learning, and Assessment, 8(6). 
Guardado, M., \& Shi, L. (2007). ESL students' experiences of online peer feedback. Computers and Composition, 24(4), 443-461.

Hall, A. (2007). Vygotsky goes online: Learning design from a socio-cultural perspective. Learning and Socio-cultural Theory: Exploring Modern Vygotskian Perspectives International Workshop, 1(1), 94-107.

Lantolf, J. P. (2000). Introducing sociocultural theory. In J. P. Lantolf (Ed.), Sociocultural theory and second language learning (pp. 1-26). Oxford, UK: Oxford University Press.

Lin, W. C. \& Yang, S. C. (2011). Exploring students' perceptions of integrating Wiki technology and peer feedback into English writing courses. English Teaching: Practice and Critique, 10(2), 88103.

Lei, Z. (2017). Salience of student written feedback by peer-revision in EFL writing class. English Language Teaching, 10(12), 151-157.

Lu, R. \& Bol, L. (2007). A comparison of anonymous versus identifiable e-peer review on college student writing performance and the extent of critical feedback. Journal of Interactive Online Learning, 6(2), 100-115.

Lumabi, B. M. (2020). Task-based dictation (TBD): A means of improving the language proficiency of college students. Middle Eastern Journal of Research in Education and Social Sciences (MEJRESS), 1(2), 116-130.

Lundstrom, K. \& Baker, W. (2009). To give is better than to receive: the benefits of peer review to the reviewer's own writing. Journal of Second Language Writing 18, 30-43

McLeod, S. (2019). Likert scale definition, examples and analysis. Simply Psychology.

Mutwarasibo, F. (2016). University students' attitudes towards peer assessment and reactions to peer feedback on group writing. Rwanda Journal, 1, 32-48.

Noroozi, O., Biemas, H. \& Mulder, M. (2016). Relations between scripted online peer feedback processes and quality of written argumentative essay. Elsevier Internet and Higher Education, $31,20-31$.

Oxford, R. (2017). Integrated skills in the ESL/EFL classroom for the AE E-teacher program. World Learning, Teaching Grammar Communicatively MOOC Module 3, 7-9.

Pablo, J. C. \& Lasaten, R. C. (2018). Writing difficulties and quality of academic essays of senior high school students. Asia Pacific Journal of Multidisciplinary Research, 6(4), 46-57.

Pena-Shaff, J. B., \& Nicholls, C. (2004). Analyzing student interactions and meaning construction in computer bulletin board discussions. Computers \& Education, 42(3), 243-265.

Pol, J. V. D., Berg, I. V. D., Admiraal, W., \& Simons, R. J. (2008). The nature, reception, and use of online peer feedback in higher education. Elsevier Computers and Education, 51(4).

Rollinson, P. (2005). Using peer feedback in the ESL writing class. ELT Journal, 59(1), 23-30.

Saeed, M. A., Ghazali, K., Sahuri, S. S., \& Abdulrab, M. (2018). Engaging EFL learners in online peer feedback on writing What does it tell us. Journal of Information Technology Education: Research, 7, 38-61.

Sihombing, R. (2016, October). Teachers' problems and solutions in assessing students' writing in senior high school level: authentic assessment or traditional assessment. In Sriwijaya University Learning and Education International Conference, 2(1), 977-992.

Thokwane, D. (2011). Using peer review to promote writing development in ESL classes. M.A. Thesis, Minnesota State University, Mankato.

University of Southern California (USC) Libraries (March 18, 2021). Research guides. Retrieved from https://libguides.usc.edu/writingguide/quantitative. 